\title{
Langerhans cell histiocytosis: the case for conservative treatment
}

\author{
J McLelland, V Broadbent, E Yeomans, M Malone, J Pritchard
}

\begin{abstract}
Fifty eight children with Langerhans cell histiocytosis who were referred to this hospital between 1980 and 1987 were studied. Fourteen had single system disease, and 44 had multisystem disease, of whom 22 had vital organ dysfunction. A conservative approach to treatment was adopted, and when systemic treatment was indicated a short course of prednisolone was used first. Eight of the patients with single system disease required no treatment, while six received local treatment alone. Eight of the patients with multisystem disease did not require systemic treatment, 17 were given prednisolone alone, and 19 were given cytotoxic drugs. Of the 14 with single system disease 13 had no long term after effects. Eight of the patients with multisystem disease died, 24 had long term after effects, and 12 had none. Outcome was related to age and Lahey score.

These results compare favourably with other series in which more aggressive approaches were used, and support our conservative approach to treatment.
\end{abstract}

Langerhans cell histiocytosis is a rare disease and all the previous large studies have included patients presenting over several decades, ${ }^{1}$ patients seen at several centres, ${ }^{2}$ or both. ${ }^{3}$ There is a wide variation in classification and treatment of patients among centres, and supportive treatments (such as antibiotics) change with time and tend to improve results. Historically, Langerhans cell histiocytosis was regarded as malignant and treated with increasingly aggressive regimens of chemotherapy. It is now generally considered to be reactive and flow cytometric studies support this view. ${ }^{4}$

Langerhans cell histiocytosis presents in different ways, and there is, as yet, no uniformly accepted classification system of extent of disease. This, combined with its rarity, means that few adequate comparative treatment studies have been carried out. At this hospital a conservative approach has been adopted since 1980. Single system bony disease is treated where possible with curettage or injection of steroids into the lesion. Multisystem disease is treated only if there is evidence of constitutional upset (fever, pain, immobility), failure to thrive or worsening disease in vital organs. Pulsed high dose prednisolone is given first, in a dose of $2 \mathrm{mg} / \mathrm{kg} /$ day for a month, and then tailed off over a two month period. ${ }^{5}$ Cytotoxic drugs, initially vinblastine or vincristine, and more recently etoposide, are used as second line agents.
The aim of this study was to look at the outcome of patients with Langerhans cell histiocytosis treated at this hospital over a relatively short time, and to see how their morbidity and mortality compared with those of published studies in which more aggressive and prolonged chemotherapy regimens were used.

\section{Patients and methods}

All patients with Langerhans cell histiocytosis who were referred to the haematology and oncology department at this hospital between 1980 and 1987 were studied. These dates were chosen as all children presenting during this period had been seen and assessed by one clinician (VB).

The age of the child at referral, sex, and the systems affected were recorded. Patients were allotted a score at initial diagnosis, using the system devised by Lahey in $1962^{2}$ and modified in $1975 .^{6}$ The type and number of courses of treatment, if any, were noted. Outcome was assessed both by allocating a score and by adding up the total number of courses of systemic treatment up to a maximum of six. Where steroids were given continuously, each three month period of treatment was regarded as a separate course. Morbidity was also assessed.

Results were analysed by regression of ordinal (dependent) data using GLIM (Royal Statistical Society).

\section{Results}

Between 1980 and 1987, 60 children with Langerhans cell histiocytosis were referred, 58 of whom had the diagnosis made by histological examination of the biopsy specimen and two who had single system disease of bone and in whom the diagnosis was made on the radiological appearance. The histopathological diagnoses were made before strict pathological guidelines were published by the Histiocyte Society, but the necessary material was not available to make definite retrospective diagnoses according to these criteria. ${ }^{7}$ Sufficient follow up information was available for 58 children.

The age range at presentation was 0 to 15 years. The distribution was skewed with a median of one year. There were 40 boys and 18 girls; 50 patients were white Europeans, six were Asians, one was oriental, and one was negroid.

EXTENT OF DISEASE

Fourteen children had single system disease; in 
13 the disease was affecting bone and in one skin. Of the 44 with multisystem disease, 22 had 'vital organ dysfunction' (lung, liver, or haemopoietic systems) as defined by Lahey. ${ }^{6}$

\section{LAHEY SCORE}

The number of patients with each Lahey score and the association between Lahey score and age is shown in table 1. Children aged 2 years or under had higher Lahey scores than those aged over 2 years at diagnosis.

\section{TREATMENT}

Of the patients with single system disease, eight had no treatment apart from a diagnostic biopsy. One was given radiotherapy, four had operations (excision of a skin plaque $(n=1)$, curettage of bone lesions $(n=2)$, and laminectomy $(n=1)$ ), and one had steroid injected into the lesion.

Of the $\mathbf{4 4}$ patients with multisystem disease, five had no treatment, one had topical mustine alone to the skin, and two had radiotherapy alone. Of 36 children treated with prednisolone, 21 also required cytotoxic drugs.

\section{OUTCOME}

Of the 14 children with single system disease, one who had radiotherapy in 1981 now has a minor periorbital deformity, but 13 have no after effects.

Of the 44 with multisystem disease, eight (two girls and six boys) died (18\%); all the children who died had been less than 2 years old at presentation, had developed vital organ dysfunction, and died within two years of pre-

Table 1 Lahey score, mortality, and age at presentation

\begin{tabular}{llll}
\hline $\begin{array}{l}\text { Age at } \\
\text { presentation } \\
\text { (years) }\end{array}$ & $\begin{array}{l}\text { No of } \\
\text { patients }\end{array}$ & $\begin{array}{l}\text { Average Lahey } \\
\text { score }\end{array}$ & $\begin{array}{l}\text { No who } \\
\text { died }\end{array}$ \\
\hline 0 & 7 & $3 \cdot 4$ & 2 \\
1 & 22 & $4 \cdot 3$ & 5 \\
2 & 7 & $2 \cdot 6$ & 0 \\
3 & 6 & $2 \cdot 3$ & 0 \\
4 & 2 & $1 \cdot 5$ & 0 \\
5 & 0 & $2 \cdot 0$ & 0 \\
6 & 1 & $2 \cdot 0$ & 0 \\
7 & 2 & $1 \cdot 0$ & 0 \\
8 & 1 & $3 \cdot 0$ & 0 \\
9 & 5 & $1 \cdot 0$ & 0 \\
10 & 1 & $1 \cdot 0$ & 0 \\
11 & 1 & $1 \cdot 0$ & \\
12 & 2 & & 0 \\
13 & 0 & 3.0 & \\
14 & 0 & & \\
15 & 1 & & \\
\hline
\end{tabular}

Table 2 Life table for patients with multisystem Langerhans cell histiocytosis

\begin{tabular}{llllll}
\hline $\begin{array}{l}\text { Interval since } \\
\text { diagnosis } \\
\text { (years) }\end{array}$ & $\begin{array}{l}\text { No of } \\
\text { deaths }\end{array}$ & $\begin{array}{l}\text { No of patients } \\
\text { alive at start of } \\
\text { interval }\end{array}$ & $\begin{array}{l}\text { Estimated } \\
\text { probability of } \\
\text { death }\end{array}$ & $\begin{array}{l}\text { Estimated } \\
\text { probability of } \\
\text { survival }\end{array}$ & $\begin{array}{l}\text { Percentage of } \\
\text { survivors at } \\
\text { the end of } \\
\text { each year }\end{array}$ \\
\hline 0 & 6 & 44 & $0 \cdot 1364$ & $0 \cdot 8636$ & 100 \\
1 & 2 & 38 & $0 \cdot 0526$ & $0 \cdot 9474$ & 86 \\
2 & 0 & 34 & 0 & 1 & 82 \\
3 & 0 & 33 & & & \\
4 & 0 & 29 & & & \\
5 & 0 & 24 & & & \\
6 & 0 & 18 & & & \\
7 & 0 & 9 & & & \\
8 & 0 & 3 & & & \\
\hline
\end{tabular}

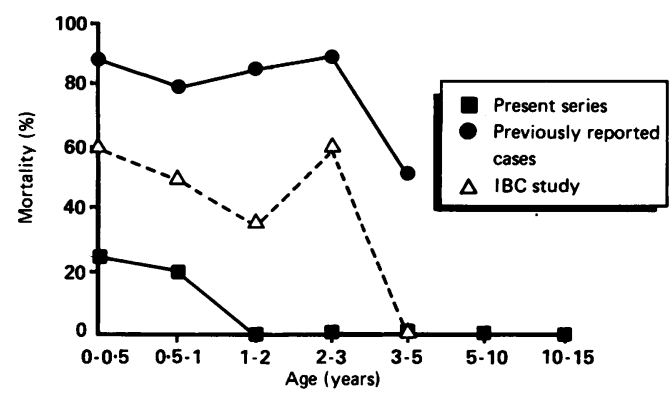

Figure 1 Age related mortality in the present series compared with the two groups reported by Lahey. ${ }^{2} I B C=$ Iowa, Baltimore, and Cincinnati.

sentation. The male:female ratio among the deaths corresponded roughly to the ratio in the whole group.

Table 1 shows the outcome and age at presentation, and table 2 is a life table of survival after diagnosis. Figure 1 shows the age related mortality in our series compared with those published in Lahey's first paper. ${ }^{2}$ The Lahey series may, however, include patients who would not be considered to have Langerhans cell histiocytosis using present diagnostic criteria. Comparison of actuarial rather than crude survival rates would have been preferable but this information is not given in other series. Table 3 shows the percentage surviving in the present series, and the Dutch-Austrian-German histiocytosis $\mathrm{X}(\mathrm{DAL}-\mathrm{HX})^{8}$ and the AEIOP studies, ${ }^{9}$ divided according to the presence or absence of vital organ dysfunction. These show that our mortality is no worse than in these other European trials in which more aggressive and prolonged treatment was used. Toogood $e t$ al reported the results of aggressive chemotherapy in 25 children, of whom 13 would have been defined by us as having multisystem disease, including five with vital organ dysfunction. ${ }^{10}$ Five children (38\%) died of overwhelming sepsis, including two in whom only bone and gingiva were affected, and who would have been unlikely to be given systemic treatment at our centre.

Twelve patients with multisystem disease (including six of the eight who were not given systemic treatment) had no long term after effects. Four had orthopaedic abnormalities alone, nine had endocrine dysfunction alone, one had hearing deficit alone, one had liver fibrosis alone, and nine had more than one of the above. Sixteen patients (36\%) had diabetes

Table 3 Two year survival in the present study, compared with the DAL-HX 83 study, and the AEIOP study ${ }^{8}$

\begin{tabular}{lc}
\hline & $\begin{array}{l}\text { No (\%) } \\
\text { survivors at } \\
\text { two years }\end{array}$ \\
\hline $\begin{array}{l}\text { Present study: } \\
\text { With organ dysfunction }\end{array}$ & $14 / 22(64)$ \\
With no organ dysfunction & $22 / 22(100)$ \\
$\begin{array}{l}\text { Dutch-Austrian-German histio- } \\
\text { cytosis X (DAL-HX) study : }\end{array}$ & \\
$\begin{array}{l}\text { With organ dysfunction } \\
\text { With no organ dysfunction }\end{array}$ & $7 / 11(64)$ \\
AEIOP study': & $26 / 26(100)$ \\
With organ dysfunction \\
With no organ dysfunction
\end{tabular}




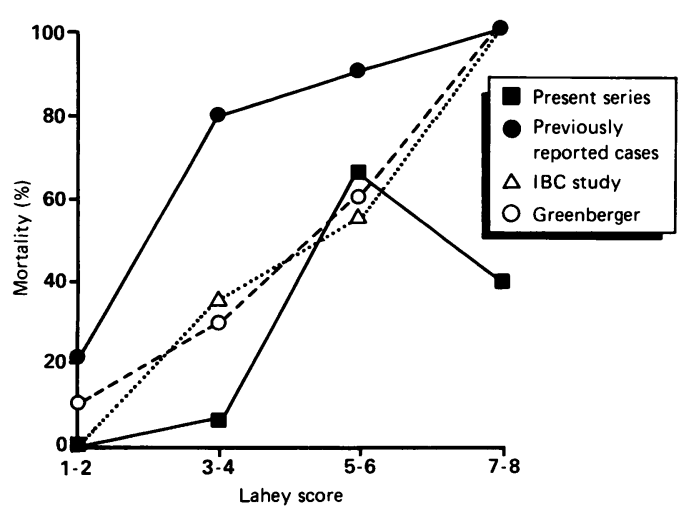

Figure 2 Mortality and maximum Lahey score in the present series compared with the two groups reported by Lahey ${ }^{2}$ (previously reported cases and IBC study) and the series reported by Greenberger et al. $.^{3} I B C=I$ lowa, Baltimore, and Cincinnati.

insipidus, which in 11 patients was associated with other disease related morbidity. In all cases chronic morbidity was the result of the disease rather than of its treatment.

The maximum Lahey score was highly significantly related to both outcome score $(p<0.001)$ and number of courses of treatment $(\mathrm{p}<0.0001)$. There was no significant association between Lahey score at presentation and either of these outcome measures. Figure 2 shows the mortality and maximum Lahey score compared with those in previously reported series.

\section{Discussion}

A child who dies of Langerhans cell histiocytosis usually does so within two years of diagnosis, either from the disease or complications of treatment. ${ }^{11}$ Of the 36 patients with multisystem disease in our series diagnosed more than two years before the analysis, seven have died. Of the eight more recently diagnosed patients still at risk, one has died; this gives an overall mortality of $14 \%$, or $36 \%$ of patients with organ dysfunction. All eight children died of progressive Langerhans cell histiocytosis, none died of the complications of treatment. Survival for the whole group of $86 \%$ compares favourably with series of children treated more aggressively with combination chemotherapy for much longer periods (table 3, figs 1 and 2).

All authors agree that children under 2 years of age who present with multisystem soft tissue disease and vital organ dysfunction as defined by Lahey have the highest mortality. The aim of treatment in these patients is to reduce this mortality, but there is no evidence that this goal is being achieved by more aggressive chemotherapy. ${ }^{10}$ The change in concept of the disease to a 'reactive condition' rather than cancer suggests the need for immune modulation rather than intensification of chemotherapy in the future.

The survival of all our patients with single system disease is not unusual, but it is noteworthy that this has been achieved with minimal intervention-presumably an advantage to patients.

Morbidity in our series was confined to patients with multisystem disease, apart from one child with single system periorbital bony disease who was left with a minor facial deformity. Twenty four of 36 survivors had some after effects, and this is comparable with other studies such as those of Lahey ${ }^{2}$ and Sims, ${ }^{1}$ in which more aggressive continuous treatment was used. The rate of diabetes insipidus in our group (36\% of those with multisystem disease) was similar to the $35 \%$ in Sims's study ${ }^{1}$ and four of $13(31 \%)$ in the series reported by Toogood $e t$ $a l,{ }^{10}$ but is in contrast to the $18 \%$ in the AEIOP study, and $4 \%$ in the DAL-HX study. This may reflect referral bias in our patients, or a higher percentage of patients in our series with extensive disease and higher Lahey scores. Alternatively, it may be a true consequence of our less intensive treatment. Further studies are needed, however, to determine whether aggressive or maintenance treatment prevents the development of diabetes insipidus.

There is no suggestion to date that aggressive chemotherapy prevents other long term after effects. It may, however, be both myelosuppressive and immunosuppressive, and previous regimens of chemotherapy were associated with at least a $5 \%$ risk of inducing malignancy in the long term. ${ }^{3}$

Comparing morbidity and mortality among series is hampered by the lack of uniformly accepted methods for evaluation of the extent of disease, and of the response to treatment. A working group of the Histiocyte Society is currently studying this question. With a 'common language' the way would be open for both useful comparisons and international studies, preferably randomised. Until that time we suggest that those caring for patients with Langerhans cell histiocytosis should consider a conservative, rather than an aggressive, approach. Nevertheless, it is critical that initial referral should be to a major centre with a commitment to clinical and basic research in Langerhans cell histiocytosis. Centralisation of tissue and data should advance the day when the mechanism of the disease is understood and rational treatment designed. 'Shared care' arrangements can and should be made when long distance referral is necessary.

1 Sims DG. Histiocytosis X. Follow-up of 43 cases. Aich Dis Child 1977:52:433-40.

2 Lahey ME. Prognosis in reticuloendotheliosis in children. $\mathcal{J}$ Pediatr 1962;60:664-71.

3 Greenberger JS, Crocker AC, Vawter G, et al. Results of treatment of 127 patients with systemic histiocytosis (Letterer-Siwe syndrome, Schuller-Christian syndrome and multifocal eosinophilic granuloma). Medicine 1981;60: 311-38.

4 McLelland J, Newton JA, Malone M, Camplejohn R, Chu AC. A flow cytometric study of Langerhans cell hisChu AC. A flow cytometric study of Langer
tiocytosis. Br $\mathcal{F}$ Dermatol 1989;120:485-91.

5 Broadbent V, Pritchard J. Histiocytosis X - current controversies. Arch Dis Child 1985;60:605-7.

6 Lahey ME. Histiocytosis $\mathrm{X}$ - an analysis of prognostic factors. I Pediatr 1975;87:184-9.

7 Writing Group of the Histiocyte Society. Histiocytosis syndromes in children. Lancet 1987; i:208-9.

8 Gadner H, Heitger A, Ritter J, et al. LangerhanszellHistiozytose im Kindesalter-Ergebnisse der DAL-HX 83 Studie. Klin Padiatr 1987;199:173-82.

9 Ceci A, Marsoni S, Colella R, et al. Langerhans cell histiocytosis in childhood, results of AEIOP-HX83 studies. Med Pediatr Oncol (in press).

10 Toogood IRG, Ellis WM, Ekert H. Prognostic criteria, treatment and survival in disseminated histiocytosis X. Aust Paediatr $\mathcal{F}$ 1979;15:91-5.

11 McLelland J, Pritchard J, Chu AC. Current controversies. In: Osband ME, Pochedly C, eds. Histiocytosis X. Philadelphia: WB Saunders, 1987:147-62. 